\title{
Indicators of optimal soils conditions for crop growing and preserving soil fertility in Rostov region and North Caucasus under irrigation conditions
}

Viktor Zhurba ${ }^{1, *}$, Nadezhda Gordeeva ${ }^{1}$, Irina Mehantseva ${ }^{1}$, Alina Golubeva ${ }^{1}$, Yana Kabanova $^{1}$, Kamila Shapovalenko ${ }^{1}$, Milena Davydova ${ }^{1}$

${ }^{1}$ Don State Technical University 344000, Russian Federation, Rostov-on-Don, Gagarin square, 1

\begin{abstract}
The tasks of agrotechnical and land-reclamation techniques in creating favorable conditions for the agricultural crops growth are determined. Maintaining high soil fertility and good land-reclamation. Soil fertility model with optimal indicators providing a combined expanded reproduction of soil fertility is proposed. Main indicators of potential soil fertility are considered. Indicators and properties of soils are captured, the relationship between plant productivity and soils quality is made. The adverse soil properties of the North Caucasus that include alkalescency and alkalinity are determined. Complex of agrotechnical and land-reclamation techniques for improving adverse soils is proposed.
\end{abstract}

\section{Introduction}

The tasks of agrotechnical and land-reclamation techniques are to create favorable conditions for the agricultural crops growth and to maintain high soil fertility and good land-reclamation condition.

In relation to agricultural plants, the optimal soils properties should be considered such a combination of their quantitative and qualitative indicators that can maximize the use of all vital factors for plants and maximize the crops potential in their highest quality harvest $[1,5]$.

Moreover, the "optimality" criteria vary depending on the biological crops characteristics. Knowing this it is possible to obtain more agricultural products on the same soils at lower costs.

In relation to soil fertility, conditions should be optimal that ensure the preservation and maintenance of biogenic processes associated with the humus accumulation, the creation of a water-resistant structure, the accumulation of mobile nutrients in the arable layer and the maintenance of a neutral (or close to it) reaction of the soil solution.

\footnotetext{
* Corresponding author: vic.zhurba@yandex.ru
} 
The modern methods of optimizing irrigation reclamation currently include environmental hydrochemical. It is understood as the creation of a hydrochemical regime favorable for the growth of agricultural crops in the active soil layer $[1,7,10]$.

In intensive crop growing technologies that have recently been widely introduced, chemicalization is given a very important role; however, the maximum effect is achievable only with its optimal combination with all intensification factors. Physical condition of the soil-water zone is a very important indicator. Physical conditions optimization of soil fertility is a common problem in optimizing the ambient of cultivated plants.

It is completely obvious that a single indicator of soil properties cannot determine either the reclamation situation or the crop yield. Certain indicators set is needed for each zone that in general creates a favorable land-reclamation situation. This indicators set should be controllable and regulated.

Global problems of our time are closely connected with the soil cover state of the planet, its dynamics, functions in nature and bio-productivity [1,2]. This applies both to the planet and to each individual region.

\section{Materials and Methods}

The establishment of optimal parameters of soil properties and reclamation state is of practical importance. Their indicators reflect the ability of a particular ecosystem to produce maximum harvest. Deterioration of the reclamation situation reduces soil fertility and bio-productivity of the territory and may lead to its unprofitable use.

Implementation of practical tasks to increase the agricultural products yielding largely depends on the correct assessment of the potential soil fertility state, a clear idea of the optimal parameters of its main indicators and the application of the effective soil fertility management system on this basis.

Generalization of numerous scientific studies shows that three groups of main indicators of potential soil fertility are most clearly distinguished:

1. agrochemical (humus, gross and mobile forms of nitrogen, phosphorus and potassium, trace elements, $\mathrm{pH}$ of salt and water extracts from the soil, hydrolytic acidity, soil-absorbing agrophysical complex (mechanical composition, structural state, bulk density, addition density, total porosity);

2. biological (total number of microorganisms, nitrification and nitrogen-fixing ability, enzymatic activity, $\mathrm{CO}_{2}$ release intensity and cellulose decomposition).

Considering these soil fertility indicators, it should be noted that one of them (humus, gross and mobile nitrogen forms, phosphorus and potassium, trace elements, etc.) are related to the main factors of plant growth and are directly involved in the formation of biological crops, while others contribute to the creation of fertility soil and harvest formation. All these indicators are interrelated and affect soil fertility in different ways [3, $4]$.

Developing an optimal soil fertility management system, first of all requirements of the objective law of continuous, increasing soil fertility should be taken into account, as well as the laws of nutrient return to soil; the interaction of plant growth and development factors; minimum, etc. Only a comprehensive requirements consideration of these basic laws allows to develop an optimal soil fertility management system aimed at their fertility reproduction and constantly increasing agricultural productivity [5,11].

In addition, when optimizing soil fertility management, it is necessary to proceed from the following key points:

1. firstly, it is necessary to have a clear idea of the current state of potential soil fertility, its agrochemical, agrophysical and biological indicators, determined as a result of soil surveys; 
2. secondly, complete data are required on the predicted level of potential soil fertility, its optimal agrochemical, agrophysical and biological indicators (soil fertility model), established on the basis of multivariate experiments;

3. thirdly, scientifically-based set of factors (methods, techniques, measures), ensuring reproduction of soil fertility (farming system) is needed [6].

The main soil fertility management system should be a model of soil fertility with optimal indicators that together provide enhanced reproduction of soil fertility.

All existing classifications of various indicators and soil properties quantitatively reflect their relationship with plant productivity and soil quality.

The most unfavorable soil properties of the North Caucasus include alkalinity and salinity. Their negative effect is determined by the fact that in an alkaline condition the humus mobility increases the dispersion of structural aggregates occurs and the food regime worsens. The presence of even a small content $(0.001 \%)$ of $\mathrm{CO}_{3}$ ion in the soil solution is toxic for all crops $[8,10]$.

Alkalization of the soil solution may not affect their properties due to buffering to certain limits. However, with prolonged exposure to adverse facts (alkaline, ground or irrigation water, soil solutions high in sodium content), the processes go towards alkalization and solonetzization.

Alkalinity indicators are: those contained in the aqueous extract: $\mathrm{CO}_{3}, \mathrm{HCO}_{3}, \mathrm{pH}$, and exchangeable sodium in the soil absorption complex. Indicators of the optimal soils state are criteria characterizing non-alkaline soils, ensuring maximum harvest. Optimal pH values of the soil are determined by biological characteristics (table 1).

Alkalines without land reclamation in all respects are far from the optimum state for the development of most agricultural crops. Therefore, when the soils of salsuginous complexes are involved in irrigation, their reclamation is necessary (table 2).

Moisture physical soils ripeness, which allows their processing, is one of the optimal indicators of alkalines that can be named. Due to unfavorable water-physical and physicalchemical parameters, it is within rather narrow limits: on neutral salt licks from about 20 to 25 , on soda $16-21 \%$. The upper limit of the sodium content in the soil absorption complex, providing optimal conditions for the development of crops is in a range of 5-10\% $[5,9]$.

Table 1 - Soil alkalinity classification

\begin{tabular}{|l|c|c|c|c|c|}
\hline \multicolumn{1}{|c|}{ Degree of alkalinity } & $\begin{array}{c}\mathrm{HCO}_{3} ; \\
\mathrm{Na} \mathrm{Mg} \\
\mathrm{Mg} / 100 \mathrm{~g}\end{array}$ & $\begin{array}{c}\mathrm{pH} \\
\text { aqueous } \\
\text { suspension } \\
1: 2,5\end{array}$ & $\begin{array}{c}\text { Exchange } \\
\mathrm{Na} \% \\
\text { from the } \\
\text { volume }\end{array}$ & $\begin{array}{c}\text { Wheat } \\
\text { harvest }\end{array}$ & $\begin{array}{c}\text { Soil fertility, } \\
\%\end{array}$ \\
\hline Не щелочные & 0,7 & 7,5 & 5,0 & $30-55$ & до 100 \\
\hline Слабо щелочные & 1,0 & 8,0 & 1,0 & $20-25$ & 85 \\
\hline Средне щелочные & 1,6 & 8,5 & 15 & $15-20$ & 65 \\
\hline Сильно щелочные & 2,0 & 9,0 & 20 & $10-15$ & 50 \\
\hline Очень сильно щелочные & 2,0 & 9,0 & 20 & до 10 & 30 \\
\hline
\end{tabular}

Signs of soil salinity are enhanced when magnesium prevails over calcium more than twice and the sodium content exceeds $5 \%$ of the absorption capacity

Soils of salsuginous complexes in relation to the predominance of the alkaline reaction of the soil solution in them, they differ in the unsatisfactory structural state of the arable and subsurface horizons. Therefore, even after loosening and processing, they quickly condense to the state of a highly densified arable land. After land-reclamation, that includes the whole range of measures: the introduction of calcium-containing ameliorant, manure, cultivation, the bulk mass of alkaline chestnut and chernozem zones decreases to 25-1.30 
$\mathrm{t} / \mathrm{m}^{3}$, which allows getting crops close to zonal soils. The density decrease of reclaimed alkalines is sometimes restrained by the low (2-2.5 less often 3\% humus content, which although it increases after reclamation, but this process is rather slow.

The gradation limits of slightly, medium, and highly saline lands depend on the salinity chemistry, which is reflected in the classification of soils by population. Depending on the salinity chemistry, the upper limit of both the total amount of salts and its individual ions also depends.

Table 2-soil water Resistance

\begin{tabular}{|l|c|}
\hline \multicolumn{1}{|c|}{ Soil category } & Water resistance, $\mathrm{mg}$ per $100 \mathrm{~g}$ of soil \\
\hline Does not have water resistance & $0-10$ \\
\hline Very weak water resistance & $11-20$ \\
\hline Weak water resistance & $21-35$ \\
\hline Average water resistance & $36-50$ \\
\hline High water resistance & $>51$ \\
\hline
\end{tabular}

According to the existing classification for the chloride-sulfate type of salt composition of soils, the content of water-soluble salts (on average for a layer of $0-100 \mathrm{~cm}$ to $0.25 \%$ ensures good growth and development of plants (no attacks, normal harvest); this includes slightly saline soils. Weak oppression (no plants lunge, harvest reduction by $10 \ldots 20 \%$ ) is observed with a salt content of $0.25 \ldots 0.40 \%$ (weak salinity). Average suppression (plant attacks and harvest reduction by $20 \ldots 50 \%$ at a salt content of $0.40 ., .0 .70 \%$ (average salinity); severe inhibition at $0.70 \ldots 1.20 \%$ (strong salinity) and salt marshes more than $1.20 \%$ (the crop is practically absent) (table 3 ).

As can be seen, excessive salts accumulation in the soil can cause salt poisoning and plants death. Sodium chlorides and sodium sulphate, soda as harmful readily soluble salts are most often found in soils. Significant inhibition of agricultural plants during soda salinization begins when the content of $\mathrm{HCO}_{3}$ ion in the amount of $0.08 \%$ and a $\mathrm{pH}$ of 8.8 9.0. With a content of $0.1-0.2 \% \mathrm{HCO}_{3}$ and at $\mathrm{pH}$ of 9.5-10.0, crop plants usually die. With chloride salinization, noticeable inhibition begins when the chlorine ion content is 0.04 $0.08 \%[5,9]$.

The effect of readily soluble salts on plants is diverse. When they get to the root with water, they destroy plant cells, affect the generative organs, compete with nutrients and thereby cause mineral starvation. Salts in the solution increase the osmotic pressure in the cells, as a result, the plant will not absorb moisture, and the so-called physiological drought arises.

Table 3. Classification of soils according to the degree of salinity

\begin{tabular}{|c|c|c|c|c|c|}
\hline \multirow[b]{2}{*}{ Тип засоления } & \multicolumn{5}{|c|}{ Степень засоления } \\
\hline & 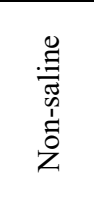 & 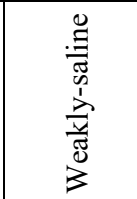 & 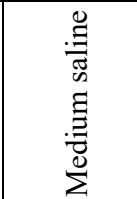 & 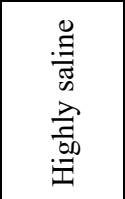 & 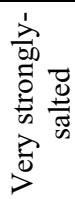 \\
\hline Chloride & $<0,03$ & $0,03-0,1$ & $0,1-0,3$ & $0,3-0,6$ & $>0,6$ \\
\hline Sulfate-chloride & $<0,05$ & $0,05-0,12$ & $0,12-0,35$ & $0,35-0,7$ & $>0,7$ \\
\hline Chloride-sulfate & $<0,10$ & $0,1-0,25$ & $0,25-0,5$ & $0,5-0,9$ & $>0,9$ \\
\hline Sulphate & $<0,15$ & $0,15-, 30$ & $0,3-0,6$ & $0,6-1,4$ & $>1,4$ \\
\hline Soda-chloride and chloride-soda & $<0,1$ & $0,1-0,15$ & $0,15-0,3$ & $0,3-0,5$ & $>0,5$ \\
\hline Soda-sulphate and sulphate-soda & $<0,15$ & $0,15-0,25$ & $0,25-0,35$ & $0,35-0,6$ & $>0,6$ \\
\hline Sulphate-or chloride-hydrocarbonate & $<0,15$ & $0,15-0,30$ & $0,3-0,5$ & & \\
\hline
\end{tabular}


The salinization causes of irrigated soils lie both in natural conditions and in the negative aspects of construction and operation. Natural conditions played a negative role in a number of irrigation systems (Azovskaya, Bagaevsko-Sadkovskaya, etc.), where drainless territories in geomorphic attitude were involved in irrigation as well as areas occupied by saline soils including salsuginous complexes with alkaline and alkaline non-gypsum and deep gypsum alkaline. Under irrigation conditions, these soils caused the secondary soils salinization. Due to the salts redistribution by irrigation groundwater, they underwent secondary alkalization (soda salinization) and salinization $[5,12]$.

Secondary salinization is also largely due to the use of irrigation water with increased salinity or an unfavorable chemical composition. In the Rostov region, the Azov and Miuss irrigation systems are examples of such irrigation. The salinization in the Azov irrigation system is caused by the prolonged use of water from the Veselovsky reservoir, mainly weak, in terms of chemistry - sulfate, chloride-sulfate, soda-sulfate and sulfate-soda. On ordinary (north-Azov) chernozems of the Miussky irrigation system, during the growing season, alkalinity outbreaks are observed that are accompanied by crops inhibition and sometimes their death (for example, corn seedlings die after the first watering). The same processes were noted in the soils of the Stavropol and Krasnodar Territories during irrigation with poor quality water [5,9].

It should be noted that waters with increased salinity could be used to wash highly saline soils and salt lakes.

In addition to the general water mineralization, attention should be paid to its alkalinity, due to ions of $\mathrm{CO}_{2}, \mathrm{HCO}_{3}$ and $\mathrm{Na}$ affecting the $\mathrm{pH}$ value. At $\mathrm{pH}$ 6-7, the medium is neutral, from 7 to 7.5 - slightly alkaline, from 7.6 - 8 alkaline, more 8 - strongly alkaline.

Sodium ion can increase the alkalinity of solutions if (1).

$$
\frac{C a+M g}{N a} \geq 0,23 \cdot C
$$

where $\mathrm{C}$ is the total water mineralization, $\mathrm{g} / \mathrm{l}$;

$\mathrm{Mg}, \mathrm{Ca}, \mathrm{Na}$ are the ion content in water, $\mathrm{mg} / \mathrm{l}$.

Regarding sodium bicarbonate there is evidence that its amount should not exceed 1.25 $\mathrm{mg} / \mathrm{l}$. In the presence of sodium carbonate, their amount should not exceed $2.5 \mathrm{mg} / \mathrm{l}$. Otherwise such water cannot be used for irrigation without gypsum.

Good quality water is considered if the content of chlorine ion in it does not exceed 0.15 $\mathrm{g} / 1$.

On the soils of soda salinization and in the soda chemistry of irrigation water with a concentration of 0.3 to $1.6 \mathrm{~g} / \mathrm{l}$, it is necessary to apply chemical reclamation not only of the soil but also of irrigation water increasing the outflow of drainage water.

It is recommended to reclaim water in the soda presence in it more than $0.6 \mathrm{mg} / \mathrm{l}$ or when the sodium content in it is more than $0.6 \mathrm{mg} / \mathrm{l}$ of the cations sum.

To prevent soil alkalization by such water the ameliorant dose is calculated by the formula (2):

$$
m=\left(\frac{C_{N a} \cdot 100}{B}-C\right) \cdot K, m
$$

where $m$ is the ameliorant dose, $\mathrm{t}$ per $1000 \mathrm{~m}^{3}$ of water; $\mathrm{C}_{\mathrm{Na}}$ is the equivalent concentration in irrigation water, $\mathrm{mmol} / \mathrm{l}$;

$\mathrm{B}$ is the permissible sodium content in irrigation water, $\%$ of the total cations, not causing deterioration of soil properties from salinization; 
$\mathrm{C}$ is the molar concentration of the equivalent of all salts in irrigation water, $\mathrm{mmol} / \mathrm{l}$;

$\mathrm{K}$ is the conversion factor for this type of chemical ameliorant: for gypsum, 0.086, for sulfuric acid is 0.049 , for iron sulfate, $\mathrm{FeSO}_{4}$ is 0.139 , for limestone $\mathrm{CaCO}_{3}$ is 0.05 .

The permissible sodium content in irrigation water (B) is determined for soils that have good water-physical properties and allow a sodium content of up to $10 \%$ of the absorption capacity (3):

$$
B=\frac{26 \cdot C}{0,267+\lg C}+2
$$

For soils with poor water-physical properties and allowing their salinity to be no more than $3-4 \%$ of absorbed sodium from the cation exchange capacity of soils (4):

$$
B=\frac{125}{C+3}+38,6
$$

When the content of magnesium cations in irrigation water is more than $50 \%$ of the cations sum of calcium and magnesium, water can be improved by adding calcium ameliorants which dose can be calculated (5):

$$
m=\left(C_{M g}-C_{C a}\right) \cdot K
$$

where $m$ is the ameliorant dose, t per $1000 \mathrm{l}$ of water;

$C_{M g}$ and $C_{C a}$ are molar concentration of the equivalent of magnesium and calcium cations in water;

$K$ is the calculation coefficient for this type of chemical ameliorant.

\section{Discussion}

However, not only natural causes determined the deterioration of the reclamation state of irrigated lands. Huge role was played by non-production losses of irrigation water, which caused a rise in groundwater level and secondary soils salinization associated with technical imperfection of irrigation systems and the denial need to build drainage in the first years of irrigation on the Don $[5,9]$.

Currently, the technical systems equipment has increased significantly but it is still far from perfect. Significant work is underway to reconstruct irrigation systems in order to improve the reclamation property of irrigated lands. These works do not always give the desired effect. Repeated surveys showed that as a result of reconstruction of the groundwater level they decreased to $2.0 \ldots 2.5 \mathrm{~m}$, however, soil salinity without special measures remained high; alkalinity appeared in the upper layers, which blocked the nutrients availability to plants despite on the introduction of mineral fertilizers $[5,13]$.

As practice shows especially in recent years irrigation water quality has large impact on the reclamation state of irrigated lands when there is an increasing lack of fresh water.

In the first place the effect on the soil and plants depends on its mineralization and chemical composition and secondly on the soil properties - mechanical composition, salinization, filtration alkalinity coefficient and the water-resistant aggregates availability.

In world practice for most non-saline and non-alkalinized soils, water of good quality is considered water with the salinity of up to $0.4-0.5 \mathrm{~g} / \mathrm{l} / 25.26 /$. When the irrigation water mineralization is more than $1 \mathrm{~g} / \mathrm{l}$ it is necessary to periodically monitor the soil condition. Mineralized waters from 1 to $3 \mathrm{~g} / 1$ is dangerous for cultivated plants and more than $3 \mathrm{~g} / 1$ salinize the soil and inhibit the plants $[4,5]$.

\section{Conclusions}


- humus mobility increases, dispergation of structural aggregates occurs, food regime worsens in alkaline environment;

- $\mathrm{CO} 3$ ion $(0.001 \%)$ in the soil solution is toxic to all crops;

- long-term exposure of adverse facts (alkaline, ground or irrigation waters, soil solutions with a high sodium content) leads to alkalization and salinization of land;

-it is necessary to apply chemical reclamation not only soil but also irrigation water increasing the outflow of drainage water on the soda salinization soils and in the soda chemistry of irrigation water with a concentration of 0.3 to $1.6 \mathrm{~g} / 1$

\section{References}

1. O.Y. Shalashova, All-Russian scientific-practical Conf., 48-56 (2008)

2. E.V. Dolina, R.E. Yurkova, O.Y. Shalashova. Gelikon Publ.,41, 54-61 (2009)

3. V.N. Shchedrin, Meliovodinform Publ., 23 (2010)

4. N.I. Mishchenko, ertility, 6, 25-26 (2009)

5. L.P. Ilina, D.G. Nevidomskaya, T.N. Polshina, publishing house of yunts RAS (2010)

6. V.F. Botvinov, Production of hydraulic works. Methodical recommendations, MGAVT, 62 (2015)

7. M.D. Konstantinov, M.A. Kukhar, Reports of the Russian agricultural Academy, 6, 31-34 (2009)

8. K.V. Guber, Melioration: stages and prospects of development: Mater. International. on-Uch.-prod. Conf. Moscow, 50-58 (2009)

9. L.P. Ilyina, D.G. Nevidomska Bulletin of the southern scientific center, 4, 47-52 (2007)

10. L.P. Ilina, V.P. Kalinichenko, K.S. Sushko, Proceedings of the VI Congress of the society of soil scientists them, 412-413 (2012)

11. L.P. Ilina, I.V. Kovda, D.G. Nevidomskaya, K.S. Sushko, E.G. Morgun, Bulletin of the southern scientific center, 4, 61-72 (2014)

12. A.N. Soloviev, Y.A. Ivanov, V.I. Pakhomov, I.A. Khozyaev, D.V. Rudoi, PHENMA, 51 (2018)

13. S. Kambulov, I. Bozhko, A. Olshevskaya, MATEC Web of Conferences, 224, 05022 (2018) https://doi.org/10.1051/matecconf/201822405022 